\title{
The Effects of CD20 inhibitors therapy in comparison to TNF $\alpha$ inhibitors therapy on IL-17 in patients with active Rheumatoid Arthritis .
}

\author{
Mohammed HannoonDawood, MSc, *Halla Ghazi Mahmood, PhD, \\ **Mohammad Hadi Al-Osami. \\ *Department of Clinical Biochemistry /College of Medicine /University of Baghdad
}

\begin{abstract}
Back ground: Rheumatoid arthritis (RA) is a chronic, systemic, inflammatory disorder that may affect many tissues and organs, once a diagnosis is made, the maintreatment goals are to control disease activity and slow the rate of joint damage, in addition to minimizing pain, stiffnes, in flammation and complications. important role of IL-17 in the development of disease and can be used as a marker for monitoring of disease activity .
\end{abstract}

Aim of the Study

The aim of the present study to evaluate the effects of CD20 inhibitors therapy in comparison to effects of TNF $\alpha$ inhibitors therapy on $I L-17$ in patients with active rheumatoid arthritis .

Results:- results obtained in the present stydy showd that serum level of IL-17were also decreasesignificantly in patients treated with Rituximab group 3 (2.28) than those of group 2 Etanercept (anti-TNFa) treated group patients (3.3).

Conclution:- the role of IL-17 in the development of disease and can be used as a marker for monitoring of disease activity

Key words : $I l-17, T N F-\alpha, C D-20, R A$

\section{Introduction}

Rheumatoid arthritis (RA) is a chronic, systemic, inflammatory disorder that may affect many tissues and organs, once a diagnosis is made, the main treatment goals are to control disease activity and slow the rate of joint damage, in addition to minimizing pain,stiffnes, inflammation and complications, pharmacologic therapies that are used include : a-nonbiologic and biologic (DMARDs ).

b-adjunctive agents such as (Corticosteroids,NSAIDs , Analgesics). $\left({ }^{1}\right.$ )

From biologic treatment : - TNF $\alpha$ inhibitors: Tumor necrosis factor alpha (TNF $\alpha$ ) is a pro- inflammatory cytokine produce by macrophages and lymphocytes. $\left({ }^{2}\right)$

- Non -TNF $\alpha$ agents:Rituximab(B-Cell Depletion):B-cells are an importantinflamma-tory cell withmultiple functions in the immune response, and these are effected on :

- IL- 17: Interleukin - 17 has been implicated in the pathogenesis of a wide range of diseases, IL-17 response can be modulated by multiple cytokines. A combination treatment of Ifliximab , an anti TNF- $\alpha$ antibody, and methotrexate, an antimetabolite, is shown to significantly reduce disease along with decrease in the frequency of Th-17 cells and the levels of IL-17 in RA patients without significant response show that such anagent holds adverse effects, clinical trials aimed at inhibiting IL - 17 promise as an efficacious treatment for arthritis. $\left(^{3}\right)$

\section{Subjects and Methods:-}

70 patients were enrolled in this study their age range from $20-68$ years. The patients were divided into three groups : Group1consist of 20 RA patients received DMARDs(disease modifyinganti rheumatic drugs ), while group 2 and group 3 consists 50 patients received biological treatment : one group of them include25 patients received Etanercept ( anti - TNF $\alpha)$ and the other groupinclude 25 patients received Rituximab ( anti-CD20), with 20 healthy volunteers as control whose their ages and gender were matched with patients group. The assay employs the quantitative sandwich enzyme immunoassay technique. Antibody specific for IL-17 has been pre-coated onto a miceoplate. Standards and samples are pipetted into the wells and any IL-17 present is bound by the immobilized antibody. After removing any unbound substances, a biotin-conjugated antibody specific for IL17 is added to the wells. After washing, avidinconjugated Horseradish Peroxidase ( HRP) is added to the wells . Following a wash to remove any unbound avidin-enzyme reagent, a substrate solution is added to the wells and color develops in proportion to the amount of IL-17 bound in the initial step . The color development is stopped 
and the intensity of the color is measured. This measurement was done by ELISA technique.

\section{Results}

The results in present study showed that there is significant elevation in the median serum level of IL17 in healty control than those of RA patients table 1 and figure 1.

Table 1: Descriptive statistics of IL-17 between RA patients and healthy control group

\begin{tabular}{|c|c|c|}
\hline IL-17 & Mean \pm S.E. & P value \\
\hline Healthy control & $26.315 \pm 5.637$ & 0.01 \\
\hline RA patients & $3.943 \pm 0.617$ & \\
\hline
\end{tabular}

IL-17 ( Pg/ml ) :Interlukin - 17

S.E. :Standar Error

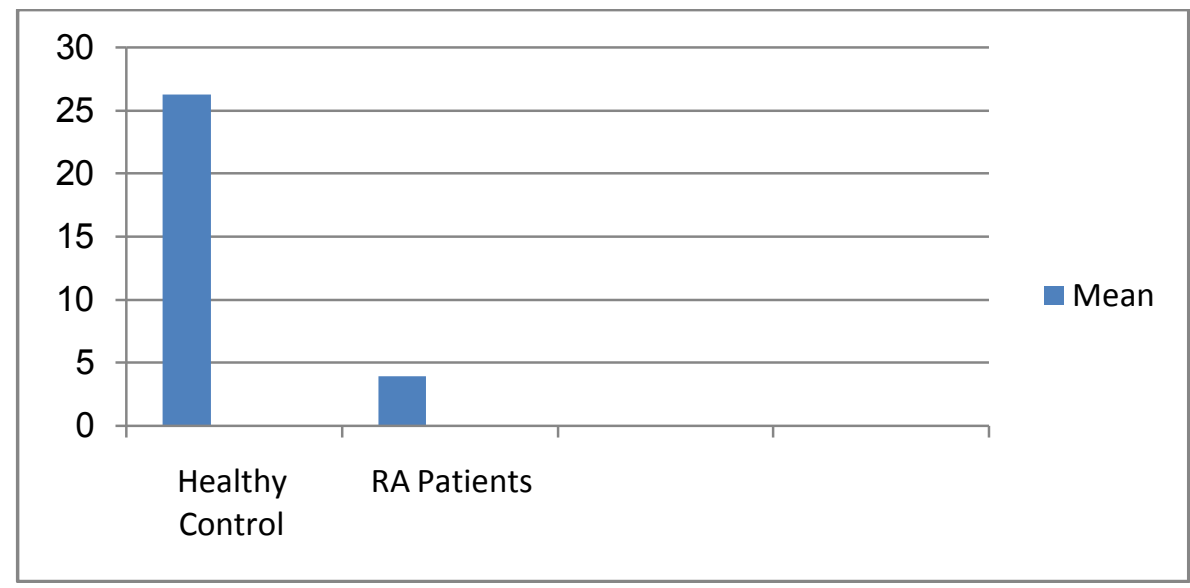

Figure 1 : Mean serum level of IL-17 in RA patients and ealthy control group

Comparison among RA groups revealed that group 1patients has higher levels of IL-17 than those of patients in group $2(5.268 \pm 0.69$ and $3.811 \pm 0.694$ respectively), and group 2 patients has higher levels ofIL17 than those of patients in group 3 , there is statistical significant difference between them every one to other $\mathrm{P}=0.01$, table 2 and figure2.

Table 2: Descriptive statistics of IL-17 in different groups of RA.

\begin{tabular}{|c|c|c|}
\hline IL-17 & Mean \pm S.E. & p-value \\
\hline Group 1 & $5.268 \pm 0.69$ & 0.01 \\
\hline Group 2 & $3.811 \pm 0.694$ & 0.01 \\
\hline Group 3 & $2.75 \pm 0.469$ & 0.01 \\
\hline
\end{tabular}

Group 1 : Not biological treatment :- treated by :

DMARDs - Disease modifying anti- rheumatic drugs- group.

Group 2 : Etanercept(anti-TNF $\alpha$ )treated group.

Group 3 : Rituximab (anti-CD20) treated group.

IL-17 : Interlukin-17

S.E. :standar Error

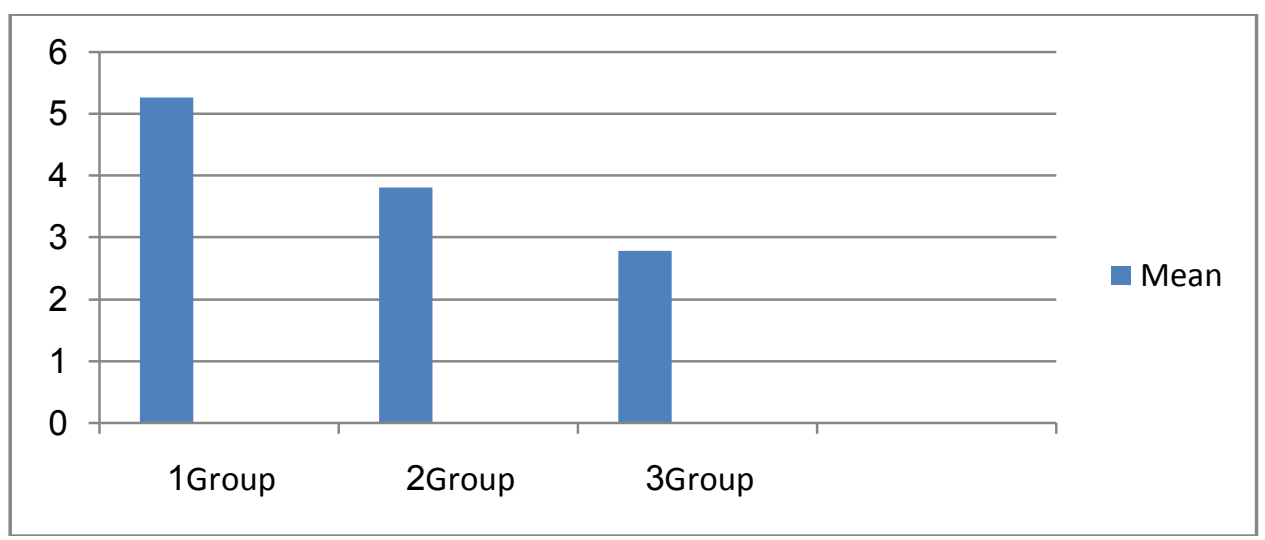

Figure 2: Mean value of IL-17 in different groups of RA. 
An anticipated median serum level of IL-17were also decreasesignificantly in patients treated with Rituximab group 3 ( 2.28 ) than those of group 2 Etanercept (anti-TNF $\alpha$ ) treated group patients (3.3)table 3 and figure 3.

Table 3 : Descriptive statistics of IL-17 between group 2 and group 3.

\begin{tabular}{|c|c|c|}
\hline Serum level of IL-17 & Group 2 & Group 3 \\
\hline Minimum & 0.33 & 0.18 \\
\hline Maximum & 16.6 & 8.52 \\
\hline Median & 3.3 & 2.28 \\
\hline Mean & 3.811 & 2.75 \\
\hline S.D. & 3.47 & 2.345 \\
\hline
\end{tabular}

Group 2 : Etanercept(anti-TNF $\alpha)$ treated group.

Group 3 : Rituximab (anti-CD20) treated group.

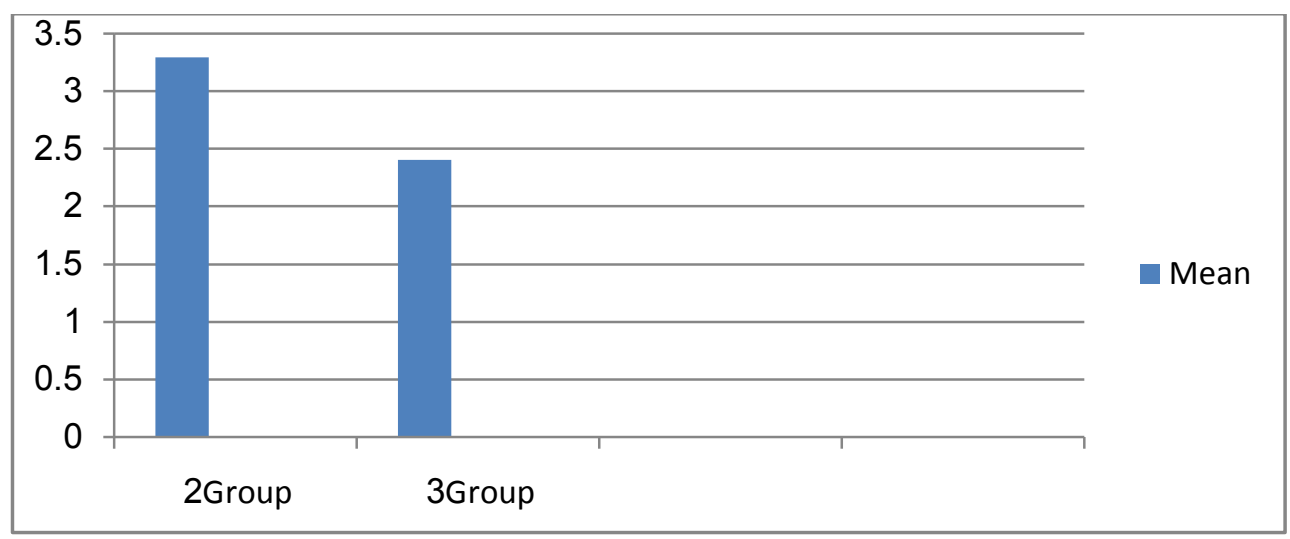

Figure 3 : Median value of Serum IL-17 in group 2 and group 3.

\section{Discussion}

Current findings suggest that the management strategy of RA disease status should be improved with an alternative regimen, inversely, patients treated with biologic therapy (Etanercept and Rituximab) showed lower serum IL-17 level when compared with healthy control or when compared with patients recivedDMARDs, $\mathrm{P}<0.01, \mathrm{P}<0.01$ respectively. These results are inagreement with results reported by other studies, who stated thatRituximab reduced the local Th 17 response in RA patients, and thedecreased Th17 response was associated with strongly reduced IL-17 as well as reduced inflammation and better clinical outcome.

These results with current findingssupport that the IL-17is highlyexpressed in the inflammatory joints and drives disease activity, implicating it as a key cytokine and potential therapeutic target .

These studies have shown that IL-17not only drives theproinflammatory response but also enhances the effect of TNF-apromoting increased destruction in the RA joint $\left({ }^{4} ;{ }^{5}\right)$.

The current study support that IL-17 implicated in pathology ofRA disease especially in active disease rather than remission or milder cases. This statement argued by several researches $\left({ }^{6} ;^{7} ;{ }^{8}\right)$

Implication of IL-17 in the RA disease may be explain withdifferent mechanisms, either by promoting matrix turnover andcartilage destruction, especially in the presence of other cytokines, mimicking the joint environment $\left({ }^{4}\right)$ mimicking the joint environment $\left({ }^{9}\right)$, or stimulate osteoclast increasing orcompletetion of proinflammatory network IL-1 and TNF- $\alpha$ inducing joint inflammation and pathology by inducingsynivium matrix destruction $\left({ }^{10}\right)$ and inducing cartilage breakdown $\left({ }^{11}\right)$

\section{References}

[1]. Anderson J, Caplan L, Yazdany J, et al,(2012) : for the American College of Rheumatology . Rheumatoid arthritis disease activity measures : American College of heumatology Recommendation for use in clinical practice. Arthritis Care Res . (Hoboken), 64:640-7.

[2]. Clifton O, et al,(2012): Rheumatoid arthritis treatment, 54(6):643-4.

[3]. Brian A, Erin H, Kamal DA, et al ,(2011): A cytokine -centric view of the pathogenesis and treatment of autoimmune arthritis ,47(4):876-8.

[4]. Moran EM, Mullan R, McCormick J,ConnolyM, Sullivan O,FitzGerald O, Bresnishan B , Veal BC and Fearon U , (2009) : Human rheumatoid arthritis tissue production of IL-17 drives matrix and cartilage degradation : synergy with tumor necrosis factor $-\alpha$, Oncostatin M and response to biologic therapies .Arthritis Research \& Therapy; 11:R113.

[5]. Moran EM , Heydrich R, Ng CT,Saber TP and McCormick J et al ., ( 2011): IL-17 Expression is localized to both mononuclear and Polymorphonuclear synovial cell infiltrate. PLoS ONE 6(8):e24048.

[6]. Mcinnes I and Schett G, (2007): Cytokines in the pathogenesis of rheumatoid arthritis. Nat Rev Immunol;7:429-42. 
[7]. Church LD, Filer AD, Hidalgo A, Howlett KA, Thomas AM, Rapecki S, Scheel - Toellner D, Buckley CD and Raza $\mathrm{K},(2010)$ : Rheumatoid synovial fluid interlukin -17 producing CD4 T-cells have abundant tumor necrosis factor $-\alpha$ coexpression, but little interlukin-22 and interlukin-23R expression . Arthritis Research \& Therapy;12:R184.

[8]. EggletonP,Bremer E, Tarr JM , De BruynM,Helfrich W, Kendall A , HaighRC, Viner NJ and Winyard PN , (2011) : Frequency of Th17CD20+ cells in the peripheral blood of rheumatoid arthritis patients is higher compared to healthy subjects.Arthritis Research \& Therapy; 13: R208.

[9]. Kotake S, Udagawa N, Takahashi N, Matsuzaki K, Itoh K, Ishiyama S, Satio S, Inoue K, Kamatani N, Gillespie MT, Martin TJ and Suda T, (1999):IL-17 in synovial fluids from patients with rheumatoid arthritis is a potent stimulator of osteoclastogenesis . J Clin Invest; 103:1345-1352.

[10]. Chabaud M, Garnero P, Dayer JM, Guerne PA, Fossiez F and Miossec P , ( 2000$)$ : Contribution of Interlukin -17 to synoviam matrix destruction in rheumatoid arthritis .Cytokine;12:1092-1099.

[11]. Koshy PJ , Henderson N, Logan C, Life PF, Cawston TE and Rowan AD , (2002): Interlukin - 17 induced cartilage collagen breakdown: novel synergistic effects in combination with pro-inflammatory cytokines. Ann Rheum Dis ; 61:704-713. 